\title{
The "Journal of Functional Morphology and Kinesiology" Journal Club Series: Highlights on Recent Papers in Exercise and Nutrition for Health
}

\author{
Mark Willems ${ }^{1, *}$, Olivier Hue ${ }^{2}$, Laura Stefani ${ }^{3}$, Silvio Lorenzetti ${ }^{4}$, Deodato Assanelli ${ }^{5}$ and \\ Marta Anna Szychlinska 6 \\ 1 Department of Sport and Exercise Sciences, University of Chichester, Chichester PO19 6PE, UK \\ 2 Department of Science and Physical Activity, University of Québec at Trois-Rivières, Québec G9A 5H7, \\ Canada; Olivier.Hue@uqtr.ca \\ 3 Sport Medicine Center, Department of Experimental and Clinical Medicine, University of Florence, \\ 50121 Florence, Italy; laura.stefani@unifi.it \\ 4 Institute for Biomechanics, Department of Health Science and Technology, ETH Zürich, 8093 Zurich, \\ Switzerland; sl@ethz.ch \\ 5 Sport-Internal Medicine, Department of Clinical and Experimental Sciences, University of Brescia, \\ 25121 Brescia, Italy; deodato.assanelli@unibs.it \\ 6 Department of Biomedical and Biotechnological Sciences, Human Anatomy and Histology Section, \\ School of Medicine, University of Catania, 95123 Catania, Italy; mszychlinska@unict.it \\ * Correspondence: m.willems@chi.ac.uk
}

Received: 27 June 2017; Accepted: 27 June 2017; Published: 29 June 2017

\begin{abstract}
We are glad to introduce the new Journal Club. This edition is focused on several relevant studies published in recent years in the field of Exercise and Nutrition for Health, chosen by our Editorial Board members. We hope to stimulate your curiosity in this field and to share with you the importance of aspects of exercise and nutrition seen also from the scientific point of view.
\end{abstract}

Keywords: exercise; physical activity; health risk factors; nutrition; supplementation; fat oxidation; weight loss; performance; lifestyle; prevention

\section{Introduction}

There is no debate that regular exercise and nutrition are key elements of a healthy lifestyle. Adoption of a healthy lifestyle reduces the risk for chronic non-communicative diseases and obesity, and is important for people of all ages. Research should provide us with observations that can guide people to make informed choice on exercise and nutrition. However, tackling chronic non-communicable diseases by adoption of a healthy lifestyle needs a multifactorial approach. Below you will find a selection of topics in the area of Exercise and Nutrition that are of interest to four members of the editorial board. The topics were not guided by the journal, and are therefore diverse in content. The Editorial Board members wish you an inspiring read.

\section{Recent Papers Regarding Exercise and Nutrition for Health}

\subsection{Green Tea and Exercise-Induced Fat Oxidation}

Highlight by Mark Willems

Green tea provides health benefits. Regular moderate-intensity exercise also provides health benefits, potentially associated with higher absolute rates of exercise-induced fat oxidation. Less than a decade ago, Venables et al. [1] provided the first evidence for enhanced fat oxidation during 
moderate-intensity exercise with acute intake of green tea extract (GTE). Twelve healthy males were supplemented with GTE capsules the day before during lunch and dinner, and in the morning about $1 \mathrm{~h}$ before exercise. The capsule contained $136 \mathrm{mg}$ epigallocatechin gallate (EGCG) and no caffeine. Fat oxidation was enhanced by $17 \%$ during 30 min cycling at $50 \%$ of maximum power output. The enhanced fat oxidation was associated with a trend for higher plasma free fatty acids $(p=0.06)$ and higher plasma glycerol $(p<0.05)$, indicating a higher rate of lipolysis. No individual responses were reported. Enhanced fat oxidation was thought to be due to inhibition of catechol-O-methyltransferase (COMT), an enzyme degrading catecholamines. However, four-phase metabolite profiling with both gas and liquid chromatography-mass spectrometry showed large inter-individual differences among healthy active males in response to GTE drink and exercise [2]. The GTE drink contained $207.5 \mathrm{mg}$ of EGCG and $120.4 \mathrm{mg}$ of caffeine. Observations indicated that a single dose of GTE did not alter COMT, but COMT activity was not measured. Subsequently, a study by Lorenz et al. [3] provided evidence that COMT activity was actually increased by $24 \%$ in healthy males and females with an acute dose of $750 \mathrm{mg}$ EGCG. Both studies by Hodgson et al. [2] and Lorenz et al. [3] will initiate future studies to address the mechanism for enhanced exercise-induced fat oxidation by green tea, with genetic predisposition to be important whether subjects are responsive to effects of green tea intake [4]. Overall, our understanding of the in vivo effects of green tea on exercise-induced fat oxidation seems to be in its infancy. Future studies on green tea and exercise-induced fat oxidation are encouraged to provide the individual responses.

\subsection{Childhood Obesity, Postural Control and Motor Skills Development: Why Physical Activity and Weight Loss Interventions are Important for Future Adulthood?}

\section{Highlight by Olivier Hue}

Global epidemic childhood obesity is considered as one of the most important public health issues in the world, and has been associated with numerous negative effects on physical health and psychological well-being, with an increased risk for persistence into later adulthood [5]. It is well known that obesity negatively affects postural control and movement (see [6] for a review). Consequently, postural control is a key factor for human standing and the execution of fine and gross motor coordinations; fundamental parts of activities of daily living. In a recent study, Dinkel et al. [7] pointed out that overweight children adopted a different postural control strategy. The authors stipulate that this altered strategy may limit motor exploration early in the development (i.e., leading to poorer motor skills acquisition). This is in accordance with previous studies showing an increased postural instability in obese children [8] and obese adolescents [9]. Moreover, D'Hondt et al. [10] reported an increasingly widening gap in gross motor coordination performances of overweight and obese children relative to normal-weight children across developmental time. The authors mentioned in conclusion that special attention is needed to promote regular participation in physical activity for overweight and obese children to improve the developement of their motor skills. More importantly, D'Hondt et al. [11] observed the effects of a multidisciplinary weight-loss intervention (moderate dietary restriction, psychological support and regular physical activity). The authors clearly demonstrated a positive effect of this intervention on the level of global motor skills scores in obese children. However, despite this positive effect, their obese children still had an average total score for motor skills that was significantly lower than the normal-weight children. In a similar vein, Sun et al. [12] claim the importance to estimate the real effects of weight management program on postural stability and neuromuscular function among obese children. We claim that it is also really urgent to continue assessing the specific effects of childhood obesity in future obese adolescents and adults on postural control and motor skills. 


\subsection{Exercise and Nutrition Effects for Health}

Highlight by Laura Stefani

Interaction between nutrition and exercise has been largely investigated in literature among athletes and also in the general population. They both contribute for enhanching sports performance and wellness [13]. More than just calories, nutrition means the correct introduction of microelements and macroelements in terms of the principal components of the diet. Human energy consists of Carbohydrates-the main energy food; Fat-an important energy source during exercise; Protein — the tissue builder; Vitamins—-the organic regulators; Minerals—the inorganic regulators; and Water-electrolytes involved in the basic regulators of temperature. Energy balance represents therefore the principal fuel for exercise [14]. Inadequate adhesion to correct nutritional habits, and eating disorders are described in children as well as in adults. This aspect can contribute, over a long term period, to the origin of sarcopenia, if not adequately supported by a normal level of daily physical activity, especially in the form of an organized form of "Exercise". In both of these categories of subjects, this aspect can limit sports activity or programmed physical activity, limiting global performance and health [15]. The term "Exercise" needs a correct definition that contributes to distinguishing it from sport's characterization. Sport means competition, and also a trend to improve and to optimize athletic performance. On the contrary, "Exercise" is a complex and structured combination of physical activities, characterized by repeated body movements (exercises) aimed at maintaining one or more components of well-being and fitness. Both presume preparation and training sometimes after a first clinical medical evaluation. Assesing various aspects of the combination of exercise with correct nutritional habits is relevant in Sports Medicine. Some promising programs highlight the role of the combination of resistance exercise with proper nutrition habits in preventing sarcopenia, in some cases also with protein-rich diets [16]. A new approach in Sports Medicine has emerged recently, dedicated to exercise as prescription therapy. The aim is to share knowledge toward the reduction of metabolic chronic disease [17] and also cancer [18]. Exercise can be prescribed in a supervised or unsupervised model. Particularly in cancer, the importance of optimizing the long-term follow-up, and of reducing the negative effects of prolonged chemotherapy is fundamental. Chemotherapy can produce cardiotoxicity, with an associated reduction of myocardial function and can also damage muscle integrity. These negative effects are worse if the population involved is older than 55 years old [16]. The literature has demonstrated that regular exercise, even if in unsupervised form, and proper nutrition contribute to reducing the major risk factors in cancer survivorship [19].

\subsection{Caffeine and Creatine Supplementation in Strength Exercise and Performance}

\section{Highlight by Silvio Lorenzetti}

It is well known that caffeine and creatine are supplements that are common and widely used in sports [20]. Based on reviews of the existing literature, Tarnopolsky et al. [20] found that caffeine taken before (3-6 mg/ $\mathrm{kg}$ ) or during (1-2 mg/ $\mathrm{kg}$ ) endurance exercise enhances performance through the central nervous system and direct muscle effects. Creatine monohydrate supplementation, at higher (approx. $20 \mathrm{~g} /$ day $\times 3-5$ days) or lower (approx. $5 \mathrm{~g} /$ day $\times 30$ days) doses appears to minimally but significantly enhance high-intensity sport performance and mass, and possibly also strength gains made during resistance exercise training over the first few months. Similarly, a recent review of Lanhers et al. [21] based on 53 studies showed that creatine supplementation is effective in upper limb strength performance for exercise with a duration of less than $3 \mathrm{~min}$. It is worth noting, that this finding was independent of population characteristics, training protocols, and supplementary doses or duration.

So called "energy drinks" have become popular recently. They often contain large amounts of caffeine, and sometimes taurine. The effect of these drinks on the performance in muscle strength 
and endurance, endurance exercise tests, jumping and sport-specific actions was summarized by Souza et al. [22]. These authors concluded that there is an improvement in performance, but also that the improvement is associated with the taurine dosage. Fifty-four resistance-trained males were divided into 3 groups and completed strength testing, consisting of one-rep max and repetitions to fatigue at $80 \%$ of $1 \mathrm{RM}$ for leg press and bench press [23]. The placebo, the acute coffee and the caffeine anhydrous groups, improved strength outcomes. Interestingly, neither acute coffee nor caffeine anhydrous improved strength outcomes more than the placebo. The conclusion is that coffee and caffeine anhydrous may be considered suitable pre-exercise caffeine sources for high-intensity exercise.

Therefore, it may be concluded that the use of creatine might indeed enhance the short-term performance, for instance, during strength training. In addition, caffeine can also enhance this type of performance, probably because psychological aspects play an important role.

\subsection{Who Is Going to Respond to This Need for Proper Lifestyles?}

Highlight by Deodato Assanelli

There is an increasing need for proper lifestyle diffusion, because nutrition and exercise have been demonstrated as being very effective, both in the elderly and in patients with chronic diseases. The best centers for cardiac rehabilitation in Europe have realised several studies, named Euroaspire, focused on the evaluation of the risk in patients hospitalised for ischemic heart disease, one year after discharge. These studies have been performed throughout Europe, with a good study design: results are encouraging for lipid and arterial blood pressure decreasing, but are very deceptive for results, probably due to inactivity. Euroaspire demonstrates that the incidence of obese patients and type 2 diabetics is too high, and has worsened in the last years: this is the result of a lack of interest within most European health systems for adequate investment in this field. Prevention requires more money than has previously been invested, needs to use indicators of results to measure the efficacy of interventions, and requires interaction among sport and exercise doctors, exercise physiologysts, nutritionists, psychologists, internists and other specialists in order to properly face this epidemic. Drugs are important, but Euroaspire demonstrates that we need an action for lifestyle incrementation at large [24].

\subsection{Beneficial Effects of Mediterranean Diet and Physical Activity on Articular Cartilage}

\section{Highlight by Marta Anna Szychlinska}

Healthy lifestyles, based on healthy nutrition programs and physical activity, have come to be of fundamental importance, nowadays, thanks to the great contribution of lifestyle in preventing numerous chronic and severe degenerative diseases such as osteoarthritis. Recently, the Mediterranean Diet based on the consumption of Extra Virgin Olive Oil (EVOO), with known anti-inflammatory and antioxidant properties, has increasingly been studied and taken into consideration as the ideal diet model for healthy aging. This fact finds confirmation when considering some interesting studies present in the literature. One of them is represented by the study by Musumeci et al. [25], suggesting a great beneficial effect of the combination of diet, based on EVOO consumption and mild physical activity, on articular cartilage. The study has been conducted on rat models, with mechanically induced osteoarthritis through the anterior cruciate ligament transection (ACLT). The rats, subsequent to the surgery, were fed with an EVOO-enriched diet and subjected to mild physical activity on treadmill to contrast the ACLT consequences on knee articular cartilage. The aim of the study was to evaluate the role of these components on the articular cartilage and synovial fluid expression of two proteins implicated in the development of osteoarthritis: lubricin, chondroprotective protein with lubricating properties, and Interleukin-1 (IL-1), pro-inflammatory cytokine associated with the cartilage degenerative events. The authors demonstrated, by histomorphometric, histological, immunocytochemical, immunohistochemical and biochemical analysis, that the anterior cruciate 
ligament transection determined the drastic decrease in the lubricin expression and the increased expression of IL-1 in rats, while after EVOO-based diet and physical activity, the protein expression was shown to return to the normal parameters (increased lubricin and decreased IL-1 expression), when compared to the controls. The authors concluded that the conjunction of Mediterranean Diet, based on the consumption of EVOO, and mild physical activity, have a beneficial effects on articular cartilage preservation and might represent a great preventive intervention for the cartilage degenerative disorders such as osteoarthritis.

Conflicts of Interest: The authors declare no conflict of interest.

\section{References}

1. Venables, M.C.; Hulston, C.J.; Cox, H.R.; Jeukendrup, A.E. Green tea extract ingestion, fat oxidation, and glucose tolerance in healthy humans. Am. J. Clin. Nutr. 2008, 87, 778-784. [PubMed]

2. Hodgson, A.B.; Randell, R.K.; Boon, N.; Garczarek, U.; Mela, D.J.; Jeukendrup, A.E.; Jacobs, D.M. Metabolic response to green tea extract during rest and moderate-intensity exercise. J. Nutr. Biochem. 2013, 24, 325-334. [CrossRef] [PubMed]

3. Lorenz, M.; Paul, F.; Moobed, M.; Baumann, G.; Zimmermann, B.F.; Stangl, K.; Stangl, V. The activity of catechol-O-methyltransferase (COMT) is not impaired by high doses of epigallocatechin-3-gallate (EGCG) in vivo. Eur. J. Pharmacol. 2014, 740, 645-651. [CrossRef] [PubMed]

4. Hursel, R.; Janssens, P.L.; Bouwman, F.G.; Mariman, E.C.; Westerterp-Plantenga, M.S. The role of catechol-O-methyl transferase Val(108/158)Met polymorphism (rs4680) in the effect of green tea on resting energy expenditure and fat oxidation: A pilot study. PLoS ONE 2014, 9, e106220. [CrossRef] [PubMed]

5. Daniels, S.R. The consequences of childhood overweight and obesity. Future Child. 2006, 16, 47-67. [CrossRef] [PubMed]

6. Teasdale, N.; Simoneau, M.; Berrigan, F.; Corbeil, P.; Handrigan, G.; Tremblay, A.; Hue, O. Obesity alters balance and movement control. Curr. Obes. Rep. 2013, 2, 235-240. [CrossRef]

7. Dinkel, D.; Snyder, K.; Molfese, V.; Kyvelidou, A. Postural control strategies differ in normal weight and overweight infants. Gait Posture 2017, 55, 167-171. [CrossRef] [PubMed]

8. D'Hondt, E.; Deforche, B.; De Bourdeaudhuij, I.; Lenoir, M. Childhood obesity affects fine motor skill performance under different postural constraints. Neurosci. Lett. 2008, 440, 72-75. [CrossRef] [PubMed]

9. Colné, P.; Frelut, M.L.; Pérès, G.; Thoumie, P. Postural control in obese adolescents assessed by limits of stability and gait initiation. Gait Posture 2008, 28, 164-169. [CrossRef] [PubMed]

10. D’Hondt, E.; Deforche, B.; Gentier, I.; De Bourdeaudhuij, I.; Vaeyens, R.; Philippaerts, R.; Lenoir, M. A longitudinal analysis of gross motor coordination in overweight and obese children versus normal-weight peers. Int. J. Obes. (Lond.) 2013, 37, 61-67. [CrossRef] [PubMed]

11. D'Hondt, E.; Gentier, I.; Deforche, B.; Tanghe, A.; De Bourdeaudhuij, I.; Lenoir, M. Weight loss and improved gross motor coordination in children as a result of multidisciplinary residential obesity treatment. Obesity (Silver Spring) 2011, 19, 1999-2005. [CrossRef] [PubMed]

12. Sun, F.; Wang, L.J.; Wang, L. Effects of weight management program on postural stability and neuromuscular function among obese children: Study protocol for a randomized controlled trial. Trials 2015, 16, 143. [CrossRef] [PubMed]

13. Rocks, T.; Pelly, F.; Slater, G.; Martin, L.A. The relationship between dietary intake and energy availability, eating attitudes and cognitive restraint in students enrolled in undergraduate nutrition degrees. Appetite 2016, 107, 406-414. [CrossRef] [PubMed]

14. Yannakoulia, M.; Matalas, A.L.; Yiannakouris, N.; Papoutsakis, C.; Passos, M.; Klimis-Zacas, D. Disordered eating attitudes: An emerging health problem among Mediterranean adolescents. Eat. Weight Disord. 2004, 9, 126-133. [CrossRef] [PubMed]

15. Bellisle, F. Assessing various aspects of the motivation to eat that can affect food intake and body weight control. L'Encéphale 2009, 35, 182-185. [CrossRef] [PubMed]

16. Herrema, A.L.; Westerman, M.J.; van Dongen, E.J.I.; Kudla, U.; Veltkamp, M. Qualitative Analysis of Drivers and Barriers to Adhering to an Exercise-Protein Intervention Designed to Counteract Sarcopenia. J. Aging Phys. Act. 2017, 22, 1-26. [CrossRef] [PubMed] 
17. Stefani, L.; Maffulli, N.; Mascherini, G.; Francini, L.; Petri, C.; Galanti, G. Exercise as prescription therapy: Benefits in cancer and hypertensive patients. Transl. Med. UniSa 2014, 11, 39-43. [PubMed]

18. Stefani, L.; Galanti, G.; Klika, R.J. Clinical Implementation of Exercise Guidelines for Cancer Patients: Adaptation of ACSM's guidelines to the Italian model. J. Funct. Morphol. Kinesiol. 2017, 2, 4. [CrossRef]

19. Stefani, L.; Petri, C.; Mascherini, G.; Galanti, G. Lifestyle intervention in survivors cancer patients. J. Funct. Morphol. Kinesiol. 2016, 1, 48-53. [CrossRef]

20. Tarnopolsky, M.A. Caffeine and creatine use in sport. Ann. Nutr. Metab. 2010, 57, 1-8. [CrossRef] [PubMed]

21. Lanhers, C.; Pereira, B.; Naughton, G.; Trousselard, M.; Lesage, F.X.; Dutheil, F. Creatine supplementation and upper limb strength performance: A systematic review and meta-analysis. Sports Med. 2017, 47, 163-173. [CrossRef] [PubMed]

22. Souza, D.B.; Del Coso, R.; Casonatto, J.; Polito, M.D. Acute effects of caffeine-containing energy drinks on physical performance: A systematic review and meta-analysis. Eur. J. Nutr. 2017, 56, 13-27. [CrossRef] [PubMed]

23. Trexler, T.E.; Smith-Ryan, A.E.; Roelofs, E.J.; Hirsch, K.R.; Mock, M.G. Effects of coffee and caffeine anhydrous on strength and sprint performance. Eur. J. Sport Sci. 2016, 16, 702-710. [CrossRef] [PubMed]

24. Kotseva, K.; Ryden, L.; De Backer, G.; De Bacquer, D.; Wood, D. EURObservational research programme: EUROASPIRE. Eur. Heart J. 2015, 36, 950-951. [PubMed]

25. Musumeci, G.; Trovato, F.M.; Pichler, K.; Weinberg, A.M.; Loreto, C.; Castrogiovanni, P. Extra-virgin olive oil diet and mild physical activity prevent cartilage degeneration in an osteoarthritis model: An in vivo and in vitro study on lubricin expression. J. Nutr. Biochem. 2013, 24, 2064-2075. [CrossRef] [PubMed]

(C) 2017 by the authors. Licensee MDPI, Basel, Switzerland. This article is an open access article distributed under the terms and conditions of the Creative Commons Attribution (CC BY) license (http:// creativecommons.org/licenses/by/4.0/). 